\title{
Pemanfaatan Serat Rami (Boehmeria Nivea) Sebagai Bahan Komposit Bermatrik Polimer
}

\author{
M. Muslimin Ilham ${ }^{1)}$, Hesti Istiqlaliyah ${ }^{2)}$ \\ ${ }^{1)}$ Program Studi Teknik Mesin, Universitas Nusantara PGRI Kediri \\ ${ }^{2)}$ Program Studi Teknik Mesin, Universitas Nusantara PGRI Kediri \\ E-mail:1 ${ }^{1}$ im.muslimin@ unpkediri.ac.id, ${ }^{2}$ hestiisti@ unpkediri.ac.id
}

\begin{abstract}
Abstrak
Perkembangan material teknik terutama komposit polimer yang meliputi bahanbahan baru(high-techmaterials), proses manufaktur dan aplikasi teknik dekade ini menunjukkan peningkatan yang cukup sinifikan. Masalah yang timbul seiring dengan perkembangan teknologi bahan komposit polimer tersebut adalah bagaimana memanfaatkan bahan-bahan yang sumber ketersediaannya cukup banyak yang mampu diregenerasikan untuk mengantisipasi krisis bahan terutama jenis plastik polimer, dimana tersedianya sumber bahan dipengaruhi oleh sumber minyak bumi yang tidak bisa diperbaharui. Dari sinilah timbul satu ide atau gagasan, bagaimana memanfaakan serat alam sebagai bahan penunjang atau bahan pengganti komposit yang terbuat dari polimer. Serat alam yang dipilih adalah serat rami (boihmera nivea), karena komposisi serat yang cukup bagus dibandingkan dengan serat alam yang lain. Permasalahan yang diangkat dalam penelitian ini adalah, untuk mengetahui seberapa besar kekuatantarik serat setelah mendapat proses tratment. Proses treatment yang dilakukan adalah dengan merendam serat kedalam beberapa larutan kimia, yaitu NaOH 5\%, ethanol 99\%, dan methylethyketone (MEK). Setelah proses treatment, serat kemudian diuji kekuatan tariknya. Hasil yang diperoleh dari pengujian kekuatan tarik ini adalah semakin tinggi konsentrasi $\mathrm{NaOH}$ maka akan semakin menurunkan kekuatan tarik serat. Sedangkan untuk pelarut ethanol diperoleh kekuatan tarik sebesar 1252,40 $\square$ 119,35 Mpa. dan untuk pelarut methylethylketone diperoleh kekuatan tarik sebesar 1258,81 $\square$ 218,37 MPa.
\end{abstract}

Kata Kunci: Komposit, Matrik Polimer, Rami.

\section{Abstract}

The development of technical materials, especially polymer composites that include new materials (high-tech materials), manufacturing processes and engineering applications this decade shows a significant increase. The problem that arises in line with the development of polymer composite materials technology is how to utilize materials that have quite a lot of sources that can be regenerated to anticipate material crises, especially polymer plastic types, where the availability of material sources is influenced by nonrenewable petroleum sources. From here comes an idea or idea, how to use natural fiber as a supporting material or composite substitute material made of polymer. The selected natural fiber is hemp fiber (boihmera nivea), because the composition of fiber is quite good compared to other natural fibers. The problem raised in this research is to find out how much the tensile strength of the fiber after getting the tratment process. The treatment process is done by soaking the fiber into several chemical solutions, namely $5 \% \mathrm{NaOH}, 99 \%$ ethanol, and methyl ethy ketone (MEK). After the treatment process, the fiber is then tested for tensile strength. The results obtained from testing this tensile strength are, the higher the concentration of $\mathrm{NaOH}$, the lower the tensile strength of the 
fiber. While for ethanol solvents obtained tensile strength of $1252.40 \pm 119.35 \mathrm{Mpa}$. And for the methyl ethyl ketone solvent obtained tensile strength of 1258.81 $\pm 218.37 \mathrm{MPa}$.

Keywords:composites, Polymer, Rami.

\section{PENDAHULUAN}

Isu yang berkembang tentang masalah lingkungan telah mendorong para peneliti untuk menemukan bahan-bahan baru yang memiliki sifat dan perilaku eco-friendly, bio-degradable, bio-composites, bio-material dan bio-fuels. Istilah-istilah tersebut muncul seiring dengan deklarasi PBB bahwa tahun 2009 adalah tahun The International Years of Natural Fibers (IYNF) yang telah disepakati pada bulan Desember 2006. Bahan baku yang banyak diminati dan memenuhi kriteria tersebut salah satunya adalah material komposit polimer. Material komposit ini mulai banyak digunakan dalam dunia manufaktur [1].

Masalah yang timbul seiring dengan perkembangan teknologi bahan komposit polimer tersebut adalah bagaimana memanfaatkan bahan-bahan yang sumber tersedianya cukup banyak yang mampu diregenerasikan untuk mengantisipasi krisis bahan terutama jenis plastikpolimer, dimana tersedianya sumber bahan dipengaruhi oleh sumber minyak bumi yang tidak bisa diperbaharui[2]. Solusi dari permasalahan komposit polimer tersebuat adalah dengan memberikan penguat dari serat alam yang masih banyak ditemui di sekitar kita.

Material komposit yang berpenguat serat terutama serat alam merupakan material alternatif yang sangat menguntungkan bila dibandingkan dengan material alternatif lainnya, dimana dewasa ini telah berkembang dengan cepat dan memperoleh perhatian yang serius bagi para ilmuwan. Serat alam yang digunakan adalah serat pelepah kelapa, serat aren, serat batang pisang, serat daun nenas, serat pandan, dan sebagainya [3]. Berbagai cara telah dilakukan untuk menciptakan produk dari bahan baku alamteruama turunan dari kayu [4], yang digunakan secara langsung ataupun diarangkan sebagai salah satu media karburasi baja rendah karbon [5]. Selain itu, dapat juga memanfaatkan serat alam selulosa khususnya serat rami (Boehmerianivea) sebagai bahan campuran yang mampu memberikan fungsi penguat tanpa ada polimer plastik thermo setting dan thermo plastic untuk menghasilkan material komposit yang dapat digunakan seluas-luasnya untuk 
aplikasi teknik, baik struktur maupun non-struktur.

Pemanfaatan serat alam terutama yang berbasis selulosa saat ini didominasi oleh industri sandang dan kertas saja. Namun dengan perkembangan teknologi, serat alam tersebut memiliki peluang dimanfatkan untuk aplikasi teknik dalam bentuk partly atau fullybio-composites. Serat alam yang berasal dari batang, kecuali bambu dan kayu, yang tumbuh di Indonesia atau tanaman dari daerah tropis memiliki jenis spesies dan jumlah varitas yang sangat banyak tetapi belum dimanfaatkan secara optimal untuk aplikasi teknik. Serat kayu dan bambu telah dikenal mampu digunakan sebagai material struktural [6].

Serat alam yang digunakan dalam penelitian ini adalah serat rami. Rami adalah salah satu tanaman yang berumur panjang, tumbuh baik di daerah yang memiliki cuaca hangat dan lembab dengan curah hujan yang hampir merata di sepanjang tahun. Perkembangbiakannya juga sangatlah mudah, hanya dengan biji, potongan batang atau poongan akar.

Berdasarkan latar belakang tersebut, masalah yang diidentifikasi adalah seberapa besar kekuatan tarik dari serat rami yang dijadikan sebagai bahan penguat pada komposit bermatrik polimer yang telah diberikan treatment sebelumnya dengan direndam pada $\mathrm{NaOH} 5 \%$, ethanol 99\%, dan methylethyketone (MEK).

\section{METODE PENELITIAN}

Variabel yang digunakan dalam penelitian ini ada dua, yaitu variabel tetap dan variabel bebas. Dimana variabel bebasnya adalah variasi treatmentyang diberikan pada serat (tanpa treatment, perendaman dengan menggunakan $\mathrm{NaOH} 5 \%$, ethanol 99\%, dan methylethyketone (MEK). Sedangkan untuk variabel tetapnya adalah kekuatan tarik serat akibat treatment yang diberikan.

Penelitian ini akan melalui beberapa tahapan, diantaranya dapat dilihat pada diagram alir penelitian berikut: 


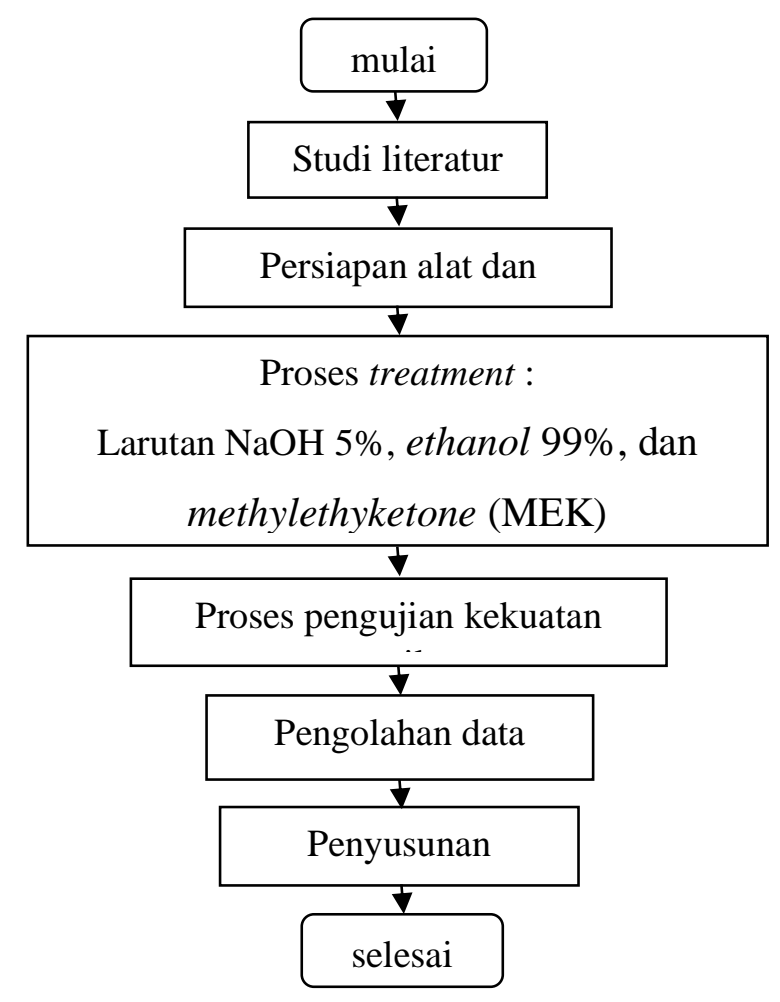

Gambar 1. Diagram Alir Penelitian

\section{HASIL DAN PEMBAHASAN}

Secara umum serat alam selulosa khususnya rami memiliki heterogenitas yang tinggi dalam hal ukuran dan sifat mekanis. Heterogenitas ini dipengaruhi oleh beberapa faktor antara lain (a) jenis varitas; (b) lokasi tumbuh;(c) kandungan unsur hara tanah dan (d) cara perawatan. Serat rami memiliki perbedaan karakter antara masa pertumbuhan muda dan masa pertumbuhan dewasa. Pertumbuhan dewasa memiliki pertumbuhan sel-sel tumbuh yang optimal sedangkan pertumbuhan muda masih memungkinkan sel-sel batang untukmembesar. Heterogenitas ini dapat mempengaruhi sifat mekanis terutama pada sifat kekuatan tarik seratnya. Selain faktor tersebut, kekuatan tarik serat tunggal juga dipengaruhi oleh perlakuan kimia pada serat. Larutan kimia yang digunakan dalam penelitian ini adalah $\mathrm{NaOH}$ 5\%, Ethanol, dan Methyl Ethyl Ketone. 
Hasil pengujian kekuatan tarik diperoleh dari pengukuran luas penampang serat membujur. Karena kesulitan mengukur luas penampang serat melintang untuk spesi menguji tarik standar ASTMD 3379 maka luasan melintang diukur secara terpisah dan hasil pengukuran luas penampang membujur dan melintang dibandingkan. Hasil perbandingan tersebut menghasilkan faktor konstanta $\mathrm{C}$ dan secara empiris menghasilkan persamaan kekuatan tarik serat tunggal rami aktual yang ditabelkan seperti yang terlihat pada tabel 1.berikut:

Tabel 1. Persamaan empiris kekuatan tarik serat tunggal rami

\begin{tabular}{|c|c|c|c|c|}
\hline \multirow{2}{*}{ No. } & \multirow{2}{*}{ Jenis serat } & \multicolumn{2}{|c|}{ Konstanta $C$} & \multirow{2}{*}{$\begin{array}{c}\text { Kekuatan tarik serat tunggal } \\
\text { aktual, MPa }\end{array}$} \\
\hline & & $C_{D}$ & $C_{A}$ & \\
\hline 1 & RAGREEN & 0,98 & 0,92 & $\mathrm{TS}_{\text {RAGREEN }}=0,92\left(\mathrm{P} / \mathrm{A}_{\mathrm{BUJUR}}\right)$ \\
\hline 2 & RANOH5 & 0,86 & 0,74 & $\mathrm{TS}_{\mathrm{RANOH}}=0,74\left(\mathrm{P} / \mathrm{A}_{\mathrm{BUJUR}}\right)$ \\
\hline 3 & RAMEK30 & 0,81 & 0,65 & $\mathrm{TS}_{\text {RAMEK30 }}=0,65\left(\mathrm{P} / \mathrm{A}_{\mathrm{BUJUR}}\right)$ \\
\hline 4 & RAMEK60 & 0,84 & 0,69 & $\mathrm{TS}_{\text {RAMEK60 }}=0,69\left(\mathrm{P} / \mathrm{A}_{\mathrm{BUJUR}}\right)$ \\
\hline 5 & RAMEK90 & 0,95 & 0,89 & $\mathrm{TS}_{\text {RAMEK90 }}=0,89\left(\mathrm{P} / \mathrm{A}_{\mathrm{BUJUR}}\right)$ \\
\hline 6 & $R A M E K 120$ & 0,95 & 0,87 & $\mathrm{TS}_{\text {RAMEK } 120}=0,87\left(\mathrm{P} / \mathrm{A}_{\mathrm{BUJUR}}\right)$ \\
\hline 7 & $R A M E K 180$ & 0,76 & 0,57 & $\mathrm{TS}_{\text {RAMEK } 180}=0,57\left(\mathrm{P} / \mathrm{A}_{\mathrm{BUJUR}}\right)$ \\
\hline 8 & RAMOL3O & 0,90 & 0,79 & $\mathrm{TS}_{\text {RAMOL30 }}=0,79\left(\mathrm{P} / \mathrm{A}_{\text {BUJUR }}\right)$ \\
\hline 9 & RAMOL60 & 0,82 & 0,67 & $\mathrm{TS}_{\text {RAMOL60 }}=0,67\left(\mathrm{P} / \mathrm{A}_{\text {BUJUR }}\right)$ \\
\hline 10 & RAMOL9O & 0,69 & 0,46 & $\mathrm{TS}_{\mathrm{RMOL90}}=0,46\left(\mathrm{P} / \mathrm{A}_{\mathrm{BUJUR}}\right)$ \\
\hline 11 & RAMOL120 & 0,98 & 0,93 & $\mathrm{TS}_{\text {RAMOL120 }}=0,93\left(\mathrm{P} / \mathrm{A}_{\mathrm{BUJUR}}\right)$ \\
\hline 12 & RAMOL180 & 0,88 & 0,78 & $\mathrm{TS}_{\text {RAMOL180 }}=0,78\left(\mathrm{P} / \mathrm{A}_{\mathrm{BUJUR}}\right)$ \\
\hline
\end{tabular}

Hasil pengujian serat rami yakni sampel serat RAGREEN, RAMEK, dan RAMOL menunjukkan perilaku dan sifat yang sangat bervariasi. Variasi perilaku dan sifat mekanis ini menjadi ciri utama serat alam dibandingkan serat buatan yang relatif memiliki sifat dan perilaku seragam.

a. Serat RANOH (Rami dan $\mathrm{NaOH}$ )

dengan meningkatkan konsentrasi larutan $\mathrm{NaOH}$ dapat menurunkan kekuatan tarik serat berbasis selulosa. Penurunan kekuatan tarik serat dipengaruhi oleh proses opening yang berlebihan dan terurainya serat tunggal menjadi microfibril akibat pelarutan lignin sebagai pengikat antar serat. Larutan alkali dengan 
konsentrasi diatas $10 \%$ menyebabkan degradasi fisik serat baik kekuatan tarik, terlepasnya ikatan antar serat dari bentuk bundle fibers dan perubahan permukaan serat. Model patahan serattunggal akan memberikan informasi keunikan perilaku serat akibat beban tarik. Sifat ulet dan getas dapat diamati langsung dari bentuk patahan ujung serat. Semakin tinggi konsentrasi $\mathrm{NaOH}$ bentuk patahan serat cenderung getas. Meskipun demikian ada beberapa faktor yang mempengaruhi hasil kekuatan tarik serat yakni cacat alami pada masa pertumbuhan serat dan akibat jamur atau bakteri sehingga serat memiliki karakteristik permukaan dan mekanis yang relatif bervariasi.

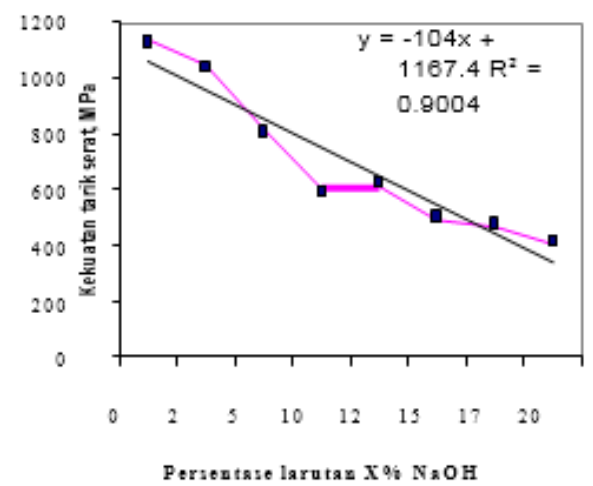

Gambar 2. Penurunan kekuatan tarik serat tunggal akibat perlakuan $\mathrm{X} \% \mathrm{NaOH}$

Signifikansi dari respon grafik penurunan kekuatan tarik serat akibat perlakuan $\mathrm{NaOH}$ dengan persentase larutan sebesar $\mathrm{X} \%$ memiliki pola persamaan linier бRANOH $=-104 \mathrm{x}+1167,4$ dengan harga faktor korelasi $\mathrm{R}^{2}=0,90$.

b. Serat RAMOL (Rami dan Ethanol)

Perubahan sifat mekanis serat akibat perlakuan lama waktu celupdi dalam media ethanol ditunjukkan pada gambar 3. Respon grafik tidak menunjukkan kecenderunganlinier. 


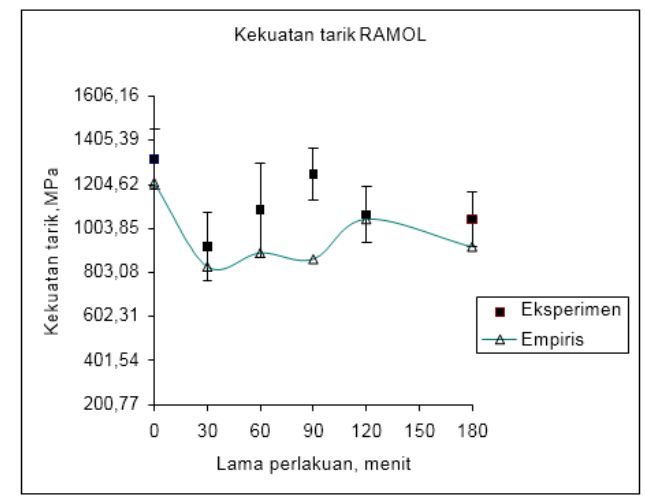

Gambar 3. Kekuatan Tarik Serat RAMOL

Kekuatan tarik tertinggi dicapai oleh RAMOL90 sebesar 1252,40 $\pm 119,35$ MPa. Sedangkan hasil perhitungan empiris nilai kekuatan tarik tertinggi adalah RAMOL120yakni1046,73+126,4Mpa.

c. Serat RAMEK (Rami dan Methyl Ethyl Ketone)

Penggunaan media sizing methylethylketones (MEK) memberikan pengaruh terhadap sifat mekanis serat RAMEK. Pengaruh lama waktu pencelupan memberikan harga beban tarik, regangan, kekuatan dan modulus elastisitas yang bervariasi. Hampir tidak ada kecenderungan linier. Dari hasil pengujian tarik serat tunggal diperoleh beban tarik dan regangan rata- rata paling rendah diperoleh oleh serat yang dikenai perlakuan selama 180 menit. Kekuatan tarik tertinggi rata-rata adalah RAMEK90 sebesar 1258,81 \pm 218,37 MPa.

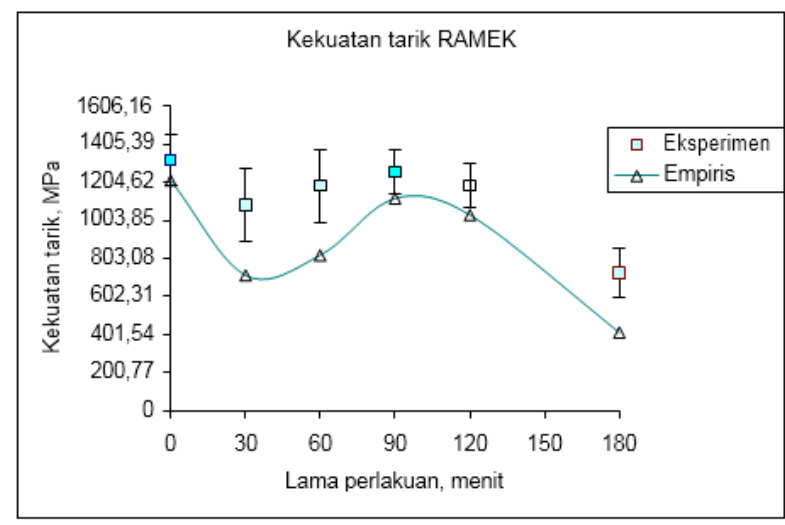

Gambar 4. Kekuatan Tarik Serat RAMEK

Dari hasil perhitungan empiris nilai tertinggi kekuatan tarik juga dicapai oleh RAMEK90. Sedangkan harga kekuatan tarik relatif paling rendah adalah

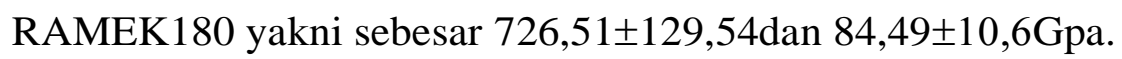




\section{KESIMPULAN}

Pemanfaatan serat alam berbasis selulosa khususnya rami untuk media penguatan pada bahan komposit matrik polimer semakin meningkat guna aplikasi teknik. Serat rami yang sumber tersedianya cukup melimpah, bio-degradable dan memiliki nilai ekonomis yang tinggi perlu diberdayakan. Agar mampu memberikan manfaat tersebut diperlukan pemahaman sifat fisika, mekanis dan kimia serat. Salah satu cara untuk meningkatkan unjuk kerja serat rami adalah dengan perlakuan permukaan yang bertujuan untuk :

a. Meningkatkan kompatibilitas serat rami yang memiliki sifat hidrophilik dengan matrik polimer hidrophobik, yakni mereduksi kandungan air serat terutama yang diserap oleh permukaan serat dengan cara sizing.

b. Hasil perlakuan permukaan serat berpengaruh terhadap kekuatan tarik serat tunggal. Dimana kekuatan tarik optimal rata-rata diatas $1000 \mathrm{MPa}$ diperoleh dari pelakuan RAMOL 90 dan RAMEK90.

\section{DAFTAR PUSTAKA}

[1] Layth, Mohammed et al., "A Review on Natural Fiber Reinforced Polymer Composite and Its Application, "International Journal of Polymer Science, 2015

[2] Marsyahyo, Eko, Perlakuan Serat Rami Dan Kompatibilitas Serat Matrik Pada Komposit Matrik Polimer, Yogyakarta: UGM Pers, 2009

[3] Sriwita, Delni A., "Pembuatan dan Karakterisasi Sifat Mekanik Bahan Komposit Serat Daun Nenas-Polyester Ditinjau dari Fraksi Massa dan Orientasi Serat", Jurnal Fisika Unad., Vol. 3,No. 1, pp. 30-36, 2014.

[4] Boimau, Kristomus, "Pengaruh Panjang Serat Terhadap Sifat Bending Papan Komposit Poliester Berpenguat Serat Buah Lontar" Jurnal Rotor Teknik Mesin Universitas Jember, 2002

[5] Istiqlaliyah, Hesti et al.,"Pengaruh Variasi Media Karburasi Terhadap Kekerasan dan Kedalaman Difusi Karbon pada Baja ST42", Prosiding Seniati, 2016.

[6] Bale, Jefriet al.,"Natural Composite Reinforced by Lontar (Borassus flabellifer) Fiber: An Experimental Study on Open-Hole Tensile Strength", International Journal of Biomaterials, 2017 